\title{
Examples of Mental Mistakes Made by Systems Engineers While Creating Tradeoff Studies
}

\author{
James Bohlman $^{1} \&$ A. Terry Bahill ${ }^{1}$ \\ ${ }^{1}$ Systems and Industrial Engineering, University of Arizona, USA \\ Correspondence: Terry Bahill, Systems and Industrial Engineering, University of Arizona, 1622 W. Montenegro, Tucson \\ AZ 85704-1822, USA. E-mail: terry@ sie.arizona.edu
}

Received: October 21, 2013 Accepted: November 4, 2013 Available online: November 21, 2013

doi:10.11114/set.v1i1.239 URL: http://dx.doi.org/10.11114/set.v1i1.239

\begin{abstract}
Problem statement: Humans often make poor decisions. To help them make better decisions, engineers are taught to create tradeoff studies. However, these engineers are usually unaware of mental mistakes that they make while creating their tradeoff studies. We need to increase awareness of a dozen specific mental mistakes that engineers commonly make while creating tradeoff studies.
\end{abstract}

Aims of the research: To prove that engineers actually do make mental mistakes while creating tradeoff studies. To identify which mental mistakes can be detected in tradeoff study documentation.

Methodology: Over the past two decades, teams of students and practicing engineers in Bahill's Systems Engineering courses wrote the system design documents for an assigned system. On average, each of these document sets took 100 man-hours to create and comprised 75 pages. We used 110 of these projects, two dozen government contractor tradeoff studies and three publicly accessible tradeoff studies. We scoured these document sets looking for examples of 28 specific mental mistakes that might affect a tradeoff study. We found instances of a dozen of these mental mistakes.

Results: Often evidence of some of these mistakes cannot be found in the final documentation. To find evidence for such mistakes, the experimenters would have had to be a part of the data collection and decision making process. That is why, in this paper, we present only 12 of the original 28 mental mistakes. We found hundreds of examples of such mistakes. We provide suggestions to help people avoid making these mental mistakes while doing tradeoff studies.

Conclusions: This paper shows evidence of a dozen common mental mistakes that are continually being repeated by engineers while creating tradeoff studies. When engineers are taught about these mistakes, they can minimize their occurrence in the future.

Keywords: validation, decision making, mistakes, design documentation

\section{Introduction}

Humans often make poor decisions. To help them be better decision-makers, engineering professors teach their students to create tradeoff studies. Tradeoff studies are broadly recognized as the method for simultaneously considering multiple alternatives with many criteria, and as such are recommended and mandated in the Capability Maturity Model Integration (CMMI®) (CMMI, 2010; Chrissis, Konrad and Shrum, 2003) Decision Analysis and Resolution (DAR) process. The decision-making fields of Judgment and Decision Making, Cognitive Science and Experimental Economics have built up a large body of research on human biases and errors in considering numerical and criteria-based choices. Relationships between experiments in these fields and the elements of tradeoff studies show that tradeoff studies are susceptible to human mental mistakes. Smith, Son, Piattelli-Palmarini and Bahill (2007) postulated 28 specific mental mistakes that could affect the ten specific components of a tradeoff study.

However, Smith et al. (2007) did not have examples from the system engineering literature. So we sought to validate their model by finding and documenting specific instances of these mental mistakes in tradeoff studies. This present paper validates the proposals of the Smith, et al. (2007). It presents real-world examples of a dozen of these mistakes. It would have been a daunting challenge to find examples of such mistakes in the open systems engineering literature, because the literature just does not publish mistakes. 


\subsection{What Are Tradeoff Studies?}

Tradeoff studies are broadly recognized and mandated as the method for simultaneously considering multiple alternatives with many criteria (Daniels, Werner \& Bahill, 2001; Smith et al., 2007). Tradeoff studies provide an ideal, rational method for choosing among alternatives. Tradeoff studies involve a mathematical consideration of many evaluation criteria for many alternatives simultaneously, in parallel.

Tradeoff studies are performed at the beginning of a project to help state the problem, select the desired system architecture and make major purchases. However, throughout a project tradeoffs are continually being made: creating team communication methods, selecting tools and vendors, selecting components, choosing implementation techniques, designing test programs, and maintaining schedule. Many of these tradeoffs should be formally documented.

The components of a tradeoff study are the (1) problem statement, (2) evaluation criteria, (3) weights of importance, (4) alternate solutions, (5) evaluation data, (6) scoring functions, (7) normalized scores, (8) combining functions, (9) preferred alternatives and (10) sensitivity analysis.

The following is a cartoon of a simple tradeoff study. The analyst is designing a system to help a baseball umpire to call balls and strikes. He is trying to select the preferred alternative. His two alternatives are a complex instrument named the Umpire's Assistant and a Seeing Eye dog. His evaluation criteria are Accuracy of the Call and Silence of Communication between the alternative systems and the umpire. (We do not want it to intrude on the classic game.) The very bottom row shows that the Umpire's Assistant was the recommended alternative.

\begin{tabular}{|l|c|c|c|}
\hline \multicolumn{3}{|c|}{ Table 1. A Generic Tradeoff Study } \\
\hline Criteria & $\begin{array}{c}\text { Weights of } \\
\text { Importance of the } \\
\text { Criteria }\end{array}$ & Alternative-1 Scores & Alternative-2 Scores \\
\hline Criterion-1 & $w t_{1}$ & $s_{11}$ & $s_{12}$ \\
\hline Criterion-2 & $w t_{2}$ & $s_{21}$ & $s_{22}$ \\
\hline $\begin{array}{l}\text { Alternative } \\
\text { Rating }\end{array}$ & & $s u m_{1}=w t_{1} \times s_{11}+w t_{2} \times s_{21}$ & $s u m_{2}=w t_{1} \times s_{12}+w t_{2} \times s_{22}$ \\
\hline
\end{tabular}

\begin{tabular}{|l|c|c|c|}
\hline \multicolumn{3}{|c|}{ Table 2. Tradeoff Study Numerical Example } \\
\hline & & \multicolumn{2}{c|}{ Alternatives } \\
\hline Evaluation Criteria & $\begin{array}{c}\text { Weights of } \\
\text { Importance }\end{array}$ & $\begin{array}{c}\text { Umpire's } \\
\text { Assistant }\end{array}$ & $\begin{array}{c}\text { Seeing } \\
\text { Eye Dog }\end{array}$ \\
\hline Accuracy of the Call & 0.75 & 0.67 & 0.33 \\
\hline Silence of Communication & 0.25 & 0.83 & 0.17 \\
\hline Sum of weight times score & & $\begin{array}{c}0.71 \\
\text { The winner }\end{array}$ & 0.29 \\
\hline
\end{tabular}

The numerical values go from 0 to 1 , with 1 being the best.

\section{Research Methodology}

Over the last quarter of a century, Bahill has sought out and collected examples of tradeoff studies. He collected 110 university projects, two dozen government contractor tradeoff studies (these reports are proprietary and cannot be published) and three publicly accessible tradeoff studies such as the San Diego Airport site selection study.

Then the authors read these reports looking for evidence of the 28 specific mental mistakes postulated by Smith et al (2007). Bohlman read all 8000 pages of the university projects and filled a database with over 800 examples of such mistakes. These examples were put into categories according to the 28 specific mental mistakes that we were looking for. After several iterations, we decided that our examples fit into only 12 of these categories. Bahill then rated each example for the perceived heuristic value, meaning the goodness of illustrating each type of mental mistake. The examples with the least perceived value were set aside. The remaining examples were compared with the original documents checking for context and accuracy. They were then re-rated based on the perceived heuristic value, uniform coverage of the dozen mental mistakes and reducing the number of different projects that would have to be explained. We created the 20 development cases that are in this paper, and another 50 cases that were used for testing. Finally, 
Bahill read the government contractor tradeoff studies and the three identified publicly accessible tradeoff studies and similarly created case studies.

Often evidence of some of these mental mistakes cannot be found in the final documentation. To find evidence for such mistakes, the experimenters would have to have been a part of the data collection and decision making process. That is why, in this paper, we present only 12 of the original 28 mental mistakes. This paper presents examples of the following mental mistakes.

\section{Using Dependent Criteria}

2. Not Stating the Problem in Terms of Stakeholder Needs

3. Vague Problem Statement

4. Substituting a Related Attribute

5. Sensitivity Analysis Mistakes

6. Forer Effect

7. Weight of Importance Mistakes

8. Anchoring and the Status Quo

9. Treating Gains and Losses Equally

10. Not Using Scoring Functions

11. Implying False Precision

12. Obviating Expert Opinion

This paper is organized as follows: for each of the above (1) the section heading announces the type of mental mistake, (2) Smith et al's (2007) explanation of the mistake is given, (3) Smith et al's (2007) recommendations for avoiding that mistake are stated, (4) the problem that the teams were modeling is explained (if it is the first time the problem has been presented), (5) an excerpt of this type of mistake is presented in the Garamond font, (6) it is explained why the particular example contains a mental mistake in the Times New Roman font, (7) a suggested rewrite is given in the Arial font. The mistake excerpts have not been edited: they are direct quotes: however, they might have been reformatted. The sections from Smith, et al. (2007) have been edited.

In the decision making literature there are hundreds of names for such mistakes, names such as attribute substitution, dominated criteria, cognitive illusions, emotions, fallacies, simplifying heuristics, fear of regret, paradoxes, herding, group think, psychological traps (Marquard \& Robinson, 2008) and cognitive biases (Sage, 1981: Smith, Piattelli-Palmarini \& Bahill, 2008; Smith \& Bahill, 2010). However, in this paper we will simply call them mental mistakes.

The purpose of this paper is to explain and give examples of certain types of mental mistakes that humans often make while doing tradeoff studies. Many of these mistakes are subtle and it is hard to avoid making them. However, it is hoped that systems analysts who read this paper will be able to recognize these mistakes in tradeoff studies created by others and to avoid these mistakes in their own tradeoff studies.

\section{Examples of Mental Mistakes in Tradeoff Studies}

This section shows examples of a dozen types of common mental mistakes that were made while doing tradeoff studies. We believe these mistakes are continually being repeated by systems engineers worldwide. We hope that reading this paper will help systems engineers to avoid such mental mistakes in the future.

\subsection{Using Dependent Criteria}

Evaluation criteria should be independent. In a tradeoff study, alternatives should be evaluated based on independent evaluation criteria. However, analysts often choose dependent criteria. When scoring these criteria for the different alternatives, having multiple dependent criteria can magnify or diminish the final scores of the alternatives, thus recommending the wrong alternative. Here are some simple examples of evaluation criteria. For evaluating humans, Height and Weight are not independent: Sex (male versus female) and Intelligence Quotient are independent. In selecting a car, the following criteria are dependent: Maximum Horse Power, Peak Torque, Top Speed, Time for the Standing Quarter Mile, Engine Size (in liters), Number of Cylinders and Time to Accelerate 0 to $60 \mathrm{mph}$ (Smith et al., 2007).

Recommendation: Dependent criteria should be grouped together as subcriteria. The seven subcriteria for the car given in the previous paragraph could all be grouped into the criteria Power. 
For each year, the class project was designed to be unprecedented, with no possible optimal solution, realistic, solved by teams of three or four engineers who would have to analyze, synthesize and evaluate alternative designs. The following example does not depend on the particular project: it could have occurred in any project.

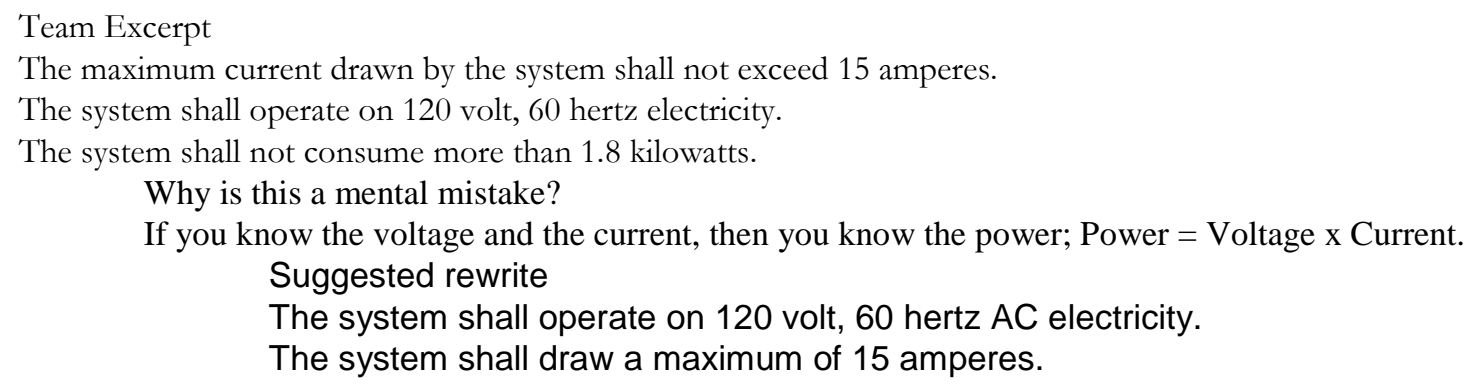

\subsection{Not Stating the Problem in Terms of Stakeholder Needs}

Committing to a class of preconceived solutions (instead of stating the true stakeholder needs) causes a lack of flexibility. Identifying the true stakeholder needs can be difficult because stakeholders often refer to both problem domains and solution domains - whichever comes most naturally. In systems engineering, the initial problem statement must be written before looking for solutions (Wymore, 1993; Smith et al., 2007).

Recommendation: Communicate with and question the stakeholders in order to determine their values and needs. State the problem in terms of customer requirements (Bahill \& Dean, 1999, 2009; Hooks \& Farry, 2001; Daniels \& Bahill, 2004; Hull, Jackson \& Dick, 2005). Later, after a better understanding of evaluation criteria and weights of importance has been gained, one must find alternative solutions that provide a good match to the requirements.

The project for 2006 was the SpinCoach ${ }^{\mathrm{TM}}$. When a spinning object (like a baseball) is put in a moving fluid (like air), it will experience a force that pushes it sideways (Bahill, Baldwin, \& Venkateswaran, 2005; Baldwin, Bahill \& Nathan, 2007; Bahill \& Baldwin, 2008; Bahill, Baldwin \& Ramberg, 2009.) Some highly successful baseball players have said and written that they see this spin of the ball and use it to track the ball with saccadic and smooth pursuit eye movements (Bahill \& Stark, 1975; Bahill \& Stark, 1977; Bahill \& LaRitz, 1984). But at present, there is no system that can teach high school and college baseball and softball players to predict this spin-induced deflection of the pitch. Therefore, this project was to design and document the design of a system that would help train baseball and softball players to pick up the spin on the ball and predict the spin's effect on the ball's deflection. The system would be capable of displaying images of spinning balls, allowing the subject to predict the spin induced deflection and providing feedback to facilitate learning. The key architectural decision in this project is whether to design the first version for baseball or softball.

\section{Team Excerpt}

The batter believes he can predict the trajectory until the ball and bat connect and therefore swing accordingly. Because of the deflection in the last milliseconds of the balls flight however, the batter is not able to adjust his swing in time to compensate and therefore the likelihood for there to be a strike called is increased because of the batter swing. In essence the pitcher is trying to fake out the batter and get him to swing at the ball or not swing at the ball based on a seemingly predictable trajectory. It appears to the batters, however that the ball seems to change direction in the last moments of its trajectory and is cause for batters to swing without connecting with the ball.

Why is this a mental mistake?

This problem statement does not mention the batter's needs. It is certainly stating correct things about what the batter and the pitcher are doing. But it fails to describe the batter's needs in terms of the system being designed. If they were designing a different system, then the excerpt might be useful. But they were supposed to be designing a system to help the batter learn the spin-induced deflection of the ball.

Suggested rewrite

Baseball and softball players need to learn how to recognize the spin of a pitched ball and use that information to predict the spin-induced deflection of the ball.

Second Team Excerpt

A video game trainer could also be used, in which a batter tries to gauge the spin on a video ball and predict where it would end up. This option could be implemented with a CD-ROM. The CD would go through the process of how to see the spin based on video taken from a laboratory. Dr. Terry Bahill, a professor in the Systems and Industrial Engineering (SIE) department at the University of Arizona, has set up a laboratory with equipment to simulate 
pitches with different types of spins. This laboratory would be a valuable resource in designing experiments to train a player to pick up the spin on a ball.

Why is this a mental mistake?

This problem statement does not mention the batter's needs.

Suggested rewrite

The top-level system function is to teach batters to recognize the spin of a pitched

ball and then use this information to predict the spin-induced movement of the ball.

\subsection{Vague Problem Statement}

If a problem statement is vague, proposed solutions could vary greatly, and derive support for very different reasons and in different ways. If a problem statement is poorly written or ambiguous, dissimilar alternative solutions could remain in the solution pool, obfuscating their rational consideration, especially if the rationale for the different psychologically attractive values of the alternative solutions are not well understood (Keeney, 1992). Failing to mention customer needs makes the problem statement seem vague (Smith et al., 2007).

Recommendation: Stating the problem is the most important and possibly the most difficult aspect of a tradeoff study. The problem should be stated in terms of the stakeholder's needs. But be sure to state the problem so that it is independent of preconceived solutions. State the problem so that it can be satisfied by a large number of alternative solutions.

The project for 2007 was the PopupCoach ${ }^{\mathrm{TM}}$. Even professional baseball players occasionally find it difficult to gracefully approach seemingly routine pop-ups. McBeath, Nathan, Bahill \& Baldwin (2008) describe a set of towering pop-ups with trajectories that exhibit cusps and loops near the apex. For a normal fly ball, the horizontal velocity is continuously decreasing due to drag caused by air resistance. But for pop-ups, the Magnus force (the force due to the ball spinning in a moving airflow) is larger than the drag force: therefore, the horizontal velocity decreases in the beginning, like a normal fly ball, but after the apex, the Magnus force accelerates the horizontal motion (Bahill $\&$ Baldwin, 2007). We refer to this class of pop-ups as paradoxical because they appear to misinform the typically robust optical control strategies used by fielders and lead to systematic vacillation in running paths, especially when a trajectory terminates near the fielder. In short, some of the dancing around when infielders pursue pop-ups can be explained as a combination of bizarre trajectories and misguidance by the normally reliable optical control strategy, rather than apparent fielder error. Former major league infielders confirm that our model agrees with their experiences. But at present, there is no methodological system that can teach high school and college baseball and softball players (more specifically catchers and infielders) to track pop-ups. Batting practice and ball games offer few opportunities for a player to learn this skill. Our customer needs a system that will provide frequent convenient opportunities to learn to field pop-ups. The goal of this project is to design and document the design of such a system.

Team Excerpt for the PopupCoach

The occurrence of pop-ups in major league games is an average of five times per game. This frequency provides reason for effective practice to be devoted to train players in order to hone their ability to catch these routine pop-ups.

Why is this a mental mistake?

This problem statement is vague.

Suggested rewrite

For baseball and softball fielders who need to catch pop-ups, the PopupCoach is a

training system that teaches fielders to track and catch pop-ups: unlike present coaches and books, the PopupCoach explains the trajectory, offers convenient practice opportunities and complements players' improvement.

Team Excerpt for the SpinCoach

The differences in (baseball) spin result in visually detectable differences in the appearance of the spinning ball as it approaches the batter. Currently, players practice the assessment of spin and trajectory prediction during actual game play and team practice sessions. This process requires coordination between multiple players, and the use of a pitcher capable of delivering a repeatable baseball pitch to the batter.

Why is this a mental mistake?

This problem statement is vague.

Suggested rewrite

For the baseball batter who needs to predict the trajectory of the pitch, the

SpinCoach is a training system that helps him to recognize the spin on the pitch and predict the ball's spin-induced movement; unlike present coaches and books, the SpinCoach shows the batter how each pitch spins and helps him to recognize this spin. 


\subsection{Substituting a Related Attribute}

Attribute substitution occurs when a subject is assessing an attribute and substitutes a related attribute that comes more readily to mind. In effect, people who are confronted with a difficult question sometimes answer an easier one instead (Kahneman, 2003). In a similar vein, when confronted with a choice among alternatives that should properly be decided by a full tradeoff study, there is a strong tendency to substitute a seemingly equivalent yet much simpler decision question in place of the tradeoff study process (Smith et al., 2007).

Recommendation: Sponsors of tradeoff studies should realize that a premature reduction of a tradeoff study process to a simpler decision question is a common heuristic that prevents consideration of the original multi-objective decision.

Team Excerpt for the SpinCoach

Use Case 2.

Name: Learn Spin-induced Deflections

Iteration: 2.3

Derived from: Concept of operations

Brief description: Player uses the SpinCoach and learns to predict the spin-induced deflection of a ball.

Added value: Player will be better able to predict the trajectory of the ball and consequently should have a higher batting average.

Second Team Excerpt for the SpinCoach

5.2.1.2 Effectiveness

The measurement of effectiveness determines the percent increase on the user's batting average over time.

The purpose of the SpinCoach is to teach batters to predict the spin-induced deflection of the baseball, but as a measure of success, these teams proposed to record the player's batting average.

Why is this a mental mistake?

What we really want to know is "Does training with the SpinCoach teach batters to predict the spin-induced deflection of the baseball?" But this is too hard to measure; therefore, our engineers substituted the player's batting average as a measure of success.

\section{Suggested rewrite}

We want to teach baseball batters to predict the spin-induced deflection of the baseball. Therefore, we want to know how well they predict the spin-induced deflection, but that is hard to measure, therefore we substitute the player's batting average as a measure of success.

In this particular design what we really want to know is "Does training with the SpinCoach teach batters to predict the spin-induced deflection of the baseball?" But this is too hard to measure; therefore, we substitute the player's batting average as a measure of success. But we $d o$ tell our readers that we are doing this.

After he received the Nobel Prize for developing Prospect Theory (RSAS, 2002; Kahneman, 2002), Kahneman spent most of his time trying to unify mental mistakes. He suggested that many or most could be explained by attribute substitution. This is a very difficult mistake to avoid. People do it all the time. The point of this section is that analysts should understand what attribute substitution is and avoid making it as a mistake. However, if the analyst really wants to use a substitute attribute, then he or she should go ahead and use it. But be sure to tell that reader that he or she is using attribute substitution.

Team Excerpt for the PopupCoach

The ability of a defending baseball team to catch pop-up balls can provide a key advantage needed to win a baseball game. That pop-ups occurs in major league games an average of five times underscores the need for players to improve their ability to catch them. Pop-ups are difficult to catch because their trajectories are irregular and it is not readily predictable where players should stand and catch them. There is no existing training system to improve players' catching percentage.

Second Team Excerpt for the PopupCoach

Thus, the need for a system to teach fielders about and offer practice scenarios involving trajectory and spin is necessary if it can help increase fielding percentages and improve the win percentages for players and teams.

Why is this a mental mistake?

What we really want to know is "Does training with the PopupCoach teach fielders to use the optimal running path and running speed while fielding fly balls. But this is too hard to measure; therefore, our engineers substituted the player's catching percentage and fielding percentages.

Suggested rewrite for the PopupCoach 
For each pop-up, we will compute the player's optimal running path and then compare it to the player's actual running path. We will also compute the optimal running speed at the time of the catch and compare this to the player's actual running speed. These two metrics will be combined to indicate how well the fielder tracked the pop-up.

Attribute substitution is a tricky mistake, because everyone does it. In this design what we really want to know is "Does training with the PopupCoach teach fielders to use the Optical Acceleration Cancellation algorithm (McBeath, Nathan, Bahill, \& Baldwin, 2008) to catch Pop-ups?" But we cannot use as a metric the probability of catching a pop-up, because 9 of our 12 alternative designs do not use real pop-ups. For these 9 designs we think it would be too expensive (if not impossible) to gather enough data for every player to make valid inferences. Furthermore we have no method of measuring the spin of pop-us. Therefore, we think variability in the speed and spin rate of real pop-ups would obscure any evidence that the fielder used the Optical Acceleration Cancellation algorithm to catch pop-ups. Because we could not measure the desired attribute, we substituted a simpler attribute, the running speed and path. Attribute substitution is not always a mistake: often it is deliberate and stated.

\subsection{Sensitivity Analysis Mistakes}

Most people are not well trained in the machinery and methods of sensitivity analysis. They often fail to compute second- and higher-order partial derivatives. When estimating partial derivatives, they often use too large a step size. When estimating partial derivatives of functions of two parameters, they often use the wrong formula; they use a formula with two instead of four numerator terms. Smith, Szidarovszky, Karnavas and Bahill (2008) has shown that interactions among parameters in tradeoff studies can be important, step sizes for the approximation of effects should be small, and second-order derivatives should be calculated accurately. It is expected that only the best-trained personnel will know of such results, illustrating the gap between truth and training (Smith et al., 2007).

Recommendation: Investments in sensitivity analysis training must be made. Perhaps enabling software can substitute for much sensitivity analysis knowledge. (Hsu, Bahill \& Stark, (1976); Karnavas, Sanchez \& Bahill, (1993); Smith, Szidarovszky, Karnavas \& Bahill, (2008) describe the development and use of sensitivity analyses.

First Team Excerpt

Since the training methods are independent of any resources and a tradeoff analysis was not required, no sensitivity analysis will be done for it.

\section{Second Team Excerpt}

The I/O performance weights more than the utilization of resources in the trade-off analysis. TW1P0 and TW2P0 values will be switched to determine the sensitivity of the design concepts to weighting and the results are shown below:

\begin{tabular}{|l|l|l|}
\hline \multirow{3}{*}{ Concept } & Weights are & Weights are \\
\cline { 2 - 3 } & $0.70 / 0.30$ & $0.30 / 0.70$ \\
\cline { 2 - 3 } & Score & Score \\
\hline 1 & 0.3811 & 0.7347 \\
\hline 2 & 0.5172 & 0.3665 \\
\hline 3 & 0.5191 & 0.3061 \\
\hline 4 & 0.568 & 0.3416 \\
\hline 5 & 0.563 & 0.3249 \\
\hline 6 & 0.6275 & 0.3362 \\
\hline 7 & 0.5739 & 0.3132 \\
\hline
\end{tabular}

Third Team Excerpt

The current trade study has an emphasis placed on the performance requirements of the SlugMaster to determine the sensitivity of results to the weighting of the requirements, a plot was constructed as a function of the two weights: I/O Performance and utilization of resources.

Why is this a mental mistake?

These Teams considered at most one parameter, the relative tradeoff weight between performance and cost.

Suggested rewrite, derived from Smith, Szidarovszky, Karnavas \& Bahill, (2008). 


\begin{tabular}{|l|c|c|c|}
\hline \multicolumn{4}{|c|}{ Table 1. A Generic Tradeoff Study } \\
\hline Criteria & $\begin{array}{c}\text { Weights of } \\
\text { Importance }\end{array}$ & Alternative 1 & Alternative 2 \\
\hline Criterion-1 & $W t_{1}$ & $S_{11}$ & $S_{12}$ \\
\hline Criterion-2 & $W t_{2}$ & $S_{21}$ & $S_{22}$ \\
\hline & & $S_{u m}=$ & $S_{1}$ \\
Alternative & & $\begin{array}{l}W t_{1} \times S_{11} \\
+W t_{2} \times S_{21}\end{array}$ & $\begin{array}{l}W t_{1} \times S_{12} \\
+W t_{2} \times S_{22}\end{array}$ \\
\hline
\end{tabular}

Table 2 gives numerical values for one particular tradeoff study, The Umpire's Assistant (http://www.sie.arizona.edu/sysengr/sie577/UmpiresAssistant.doc).

\begin{tabular}{|l|c|c|c|}
\hline \multicolumn{1}{|c|}{ Table 2. Tradeoff Study Numerical Example } \\
\hline Criteria & $\begin{array}{c}\text { Weights of } \\
\text { Importance }\end{array}$ & $\begin{array}{c}\text { Alternatives } \\
\text { Assistant }\end{array}$ & $\begin{array}{c}\text { Seeing } \\
\text { Eye } \\
\text { Dog }\end{array}$ \\
\hline $\begin{array}{l}\text { Accuracy } \\
\text { of the call }\end{array}$ & 0.75 & 0.67 & 0.33 \\
\hline $\begin{array}{l}\text { Silence of } \\
\text { Signaling }\end{array}$ & 0.25 & 0.83 & 0.17 \\
\hline $\begin{array}{l}\text { Sum of } \\
\text { weight } \\
\text { times } \\
\text { score }\end{array}$ & $\begin{array}{c}0.71 \\
\text { The } \\
\text { winner }\end{array}$ & 0.29 \\
\hline
\end{tabular}

Definition of the semirelative sensitivity function:

$\xi_{\alpha}=\left.\frac{\partial F}{\partial \alpha}\right|_{\mathrm{NOP}} \alpha_{0}$

These are the semirelative sensitivity functions for Tables 1 and 2.

$S_{W t_{1}}^{g B I_{1}}=\left(S_{11}-S_{12}\right) W t_{1}=0.26$

$S_{W t_{2}}^{g B I_{1}}=\left(S_{21}-S_{22}\right) W t_{2}=0.16$

$S_{S_{11}}^{g B I_{1}}=W t_{1} S_{11}=0.50$

$S_{S_{21}}^{g / B I_{1}}=W t_{2} S_{21}=0.21$

$S_{S_{12}}^{g / B I_{1}}=-W t_{1} S_{12}=-0.25$

$S_{S_{22}}^{g / B I_{1}}=-W t_{2} S_{22}=-0.04$

These functions show that the most important parameter is the score for alternative-1 on criteria-1. Sensitivity analyses need mathematical detail. Failure to do the mathematics right produces erroneous results. Smith, Szidarovszky, Karnavas and Bahill, (2008) present the correct mathematical equations.

For more comments about sensitivity analyses, see these online documents:

http://www.sie.arizona.edu/sysengr/sie554/SpinCoach/JA2/index.html

http://www.sie.arizona.edu/sysengr/sie554/PopUpCoach/index.html 


\subsection{Forer Effect}

According to the Forer Effect, previously existing criteria will be adopted if (1) the analyst believes that the criteria apply to the present problem, (2) the criteria are well presented and (3) the analyst believes in the authority of the previous criteria writer. For example, the analyst might fail to question or re-write criteria from a legacy tradeoff study that originated from a perceived authority and is now seemingly adaptable to the tradeoff at hand. This is called the Forer effect. Forer (1949) gave a personality test to his students. He then asked them to evaluate his personality analyses of them, supposedly based on their test's results. Students rated their analyses on a scale of 0 (very poor) to 5 (excellent) as to how well it applied to them. The average score was 4.26. Actually, Forer had given the same analysis to all the students. He had assembled this analysis of a generally likeable person from horoscopes. Variables that contribute to this fallacy in judgment are that the subject believes the analysis only applies to them, the subject believes in the authority of the evaluator, and the analysis contains mainly positive traits (Smith et al., 2007).

Recommendation: Spend time considering and formulating criteria from scratch, before consulting and possibly reusing previously written criteria.

The textbook for the course (Chapman, Bahill \& Wymore, 1992) had a primitive sensitivity analysis that only considered one parameter, the tradeoff weight between cost and performance. In Section 5.5.4 it states, "The system is sensitive to tradeoff weightings. For example changing the weights of the Trade-Off Requirement can easily sway the answer. The current trade-off puts heavy emphasis on the I/O performance of the system (0.90) and not on the utilization of resources $(0.10)$. Changing the degree of emphasis can change the results..." In the course, we had a lecture and a homework that described how to take partial derivatives and form the semirelative sensitivity functions for each parameter in the tradeoff study (Smith, Szidarovszky, Karnavas \& Bahill, 2008). However, the students repeatedly copied the method of conducting a sensitivity analysis from a legacy tradeoff study published in the course textbook. Despite warnings about the inadequacy of that sensitivity analysis, the students conducted their analyses in that very same way. This was an example of the Forer effect (Forer, 1949) Students failed to question a sensitivity analysis that was presented by a perceived authority and was seemingly adaptable to their own tradeoff study.

Team Excerpt

Tradeoff Score vs Relative Weight of Cost versus Performance

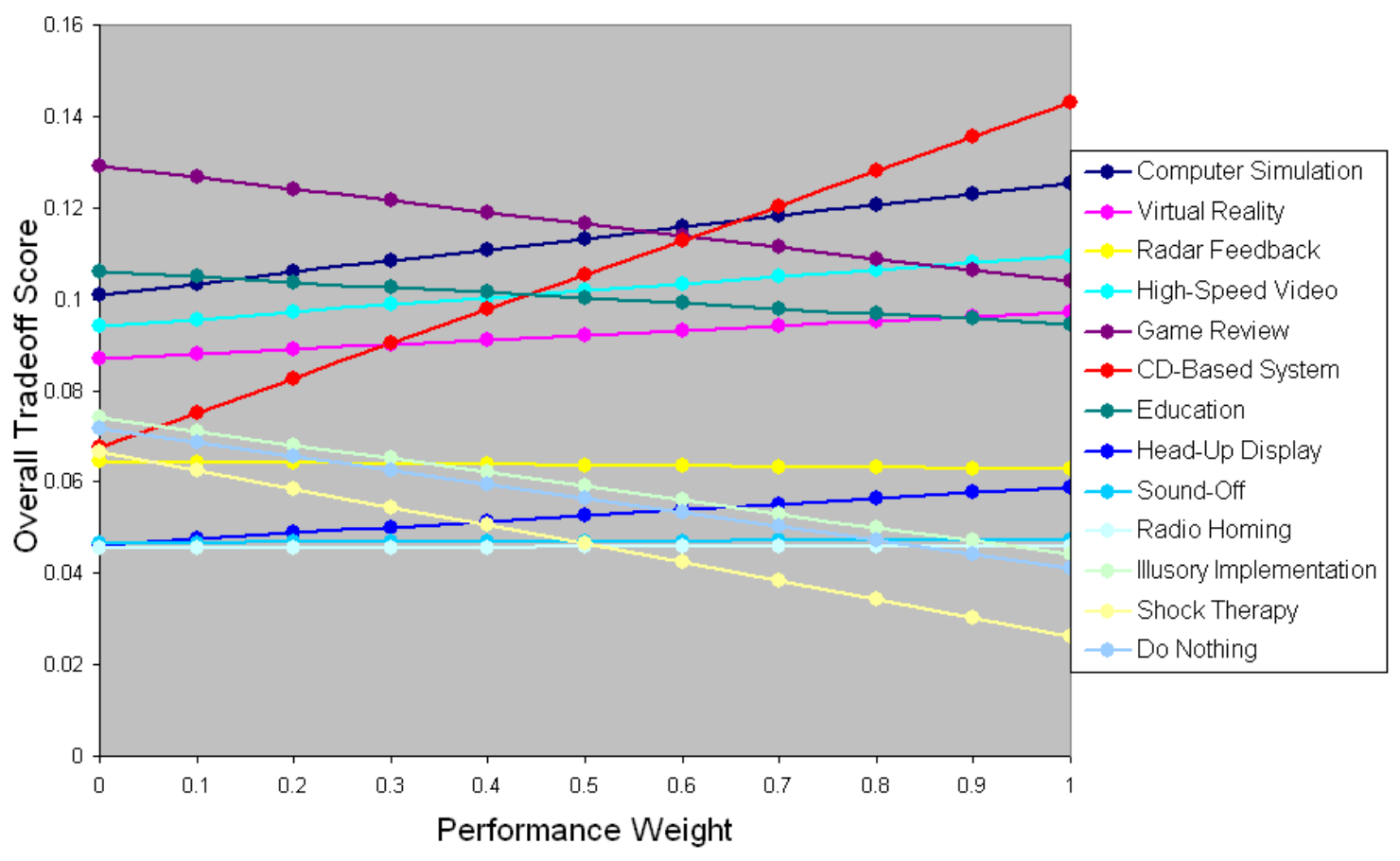

Figure 1. Team summary of a sensitivity analysis. It shows how the overall tradeoff scores vary for a dozen alternatives as the cost becomes less important and the performance becomes more important.

$$
w t_{\text {cost }}+w t_{\text {performance }}=1
$$

Why is this a mental mistake? 
The only parameter being varied here is the relative weight of performance versus cost. In this figure, the team just put their new data into a figure from their textbook (Chapman, Bahill \& Wymore, 1992). They ignored all sensitivity analyses that we developed later. Students failed to question a sensitivity analysis that was presented by a perceived authority and was seemingly adaptable to their own tradeoff study.

\subsection{Weight of Importance Mistakes}

When a group of people is asked to assign a weight of importance for an evaluation criterion, each person might produce a different value. Different weights arise not only from different preferences, but also from irrational severity amplifiers (Bahill \& Karnavas, 2000; Bahill \& Smith, 2009). These include the factors of lack of control, lack of choice, lack of trust, lack of warning, lack of understanding, manmade, newness, dreadfulness, personalization, recallability and immediacy. Excessive disparities occur when a person assesses a weight of importance after framing the problem differently. An evaluation may depend on how the criterion affects that person, how well that person understands the alternative technologies, the dreadfulness of the results, etc. As a result, each person might assign a different weight of importance to any criterion. The decision analyst should assign weights to the criteria so that the more important ones will have more effect on the outcome. Weights are often given as numbers between 0 and 10, but are usually normalized so that in each category they sum to 1.0. These methods can be used by individuals or teams. If pair-wise comparisons of preferences between the criteria can be elicited from experts, then the weights of importance can be determined through the Analytic Hierarchy Process (AHP). However, performing pair-wise comparisons can lead to intransitive preferences: Therefore, the AHP computes an inconsistency index to warn if the domain expert is giving intransitive responses (Smith et al., 2007).

Recommendation: Interpersonal variability can be reduced with education, peer review of the assigned weights, and group discussions. But be aware that people are like lemmings: if you reveal how other people are voting, then they are likely to respond with the most popular answers. It is also important to keep a broad view of the whole organization, so that criteria in one area are considered in light of all other areas. A sensitivity analysis can show how important each weight is. For unimportant weights, move on. For important weights, spend more time and money trying to get consensus: this might include showing the recommended alternatives for several different sets of weights.

The project for $\mathbf{2 0 0 5}$ was the Umpire's Assistant. For the baseball umpire who needs to call balls and strikes, the Umpire's Assistant is an intelligent decision aiding system that helps him or her to call balls and strikes accurately, consistently and in real-time. Unlike unassisted human umpires, the Umpire's Assistant uses the same strike-zone standards for all leagues, parks, umpires, batters and pitchers.

\begin{tabular}{|c|c|c|}
\hline $\begin{array}{c}\text { Utilization of Resources Figures } \\
\text { of Merit Requirements }\end{array}$ & $\begin{array}{l}\text { Weight } \\
\text { Value }\end{array}$ & $\begin{array}{c}\text { Normalized } \\
\text { weight }\end{array}$ \\
\hline 1. Available Money & 2 & 0.02326 \\
\hline 2. Available Time & 2 & 0.02326 \\
\hline $\begin{array}{l}\text { System design \& } \\
\text { prototyping by } 12 / 31 / 05\end{array}$ & 2 & 0.02326 \\
\hline $\begin{array}{l}2.2 \text { System verification testing } \\
\text { by } 2 / 06\end{array}$ & 2 & 0.02326 \\
\hline 3. Technological Restrictions & 10 & 0.11628 \\
\hline $\begin{array}{l}3.1 \text { to not significantly alter } \\
\text { the dynamics of baseball }\end{array}$ & 9 & 0.10465 \\
\hline $\begin{array}{l}3.2 \text { to comply with local, } \\
\text { regional, state, federal laws }\end{array}$ & 10 & 0.11628 \\
\hline 3.3 to comply with FCC rules & 10 & 0.11628 \\
\hline 4. Adaptability & 8 & 0.09302 \\
\hline $\begin{array}{l}4.1 \text { to comply with Standards } \\
\text { \& Specifications of MLB }\end{array}$ & 8 & 0.09302 \\
\hline $\begin{array}{l}4.2 \text { to comply with Standards } \\
\text { \& Specifications of NCAA }\end{array}$ & 8 & 0.09302 \\
\hline
\end{tabular}

Why is this a mental mistake?

The normalized weights add up to 0.826 . They should add up to 1.0 in each category and each subcategory.

Table 4. Suggested rewrite for the Umpire's Assistant 


\begin{tabular}{|c|c|c|c|}
\hline Utilization of Resources Evaluation Criteria & 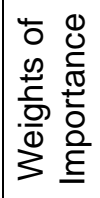 & 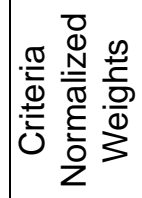 & 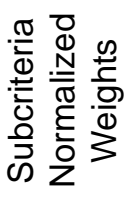 \\
\hline 1. Available Money & 2 & 0.09 & \\
\hline 2. Available Time & 2 & 0.09 & \\
\hline $\begin{array}{rllll}2.1 & \text { System design \& prototyping by } \\
12 / 31 / 05 & & & & \end{array}$ & 2 & & 0.5 \\
\hline 2.2 System verification testing by $2 / 14 / 06$ & 2 & & 0.5 \\
\hline 3. Technological Restrictions & 10 & 0.45 & \\
\hline $\begin{array}{c}3.1 \text { to not significantly alter baseball } \\
\text { dynamics }\end{array}$ & 9 & & 0.31 \\
\hline 3.2 to comply with local, state $\&$ federal laws & 10 & & 0.35 \\
\hline 3.3 to comply with FCC rules & 10 & & 0.35 \\
\hline 4. Adaptability & 8 & 0.36 & \\
\hline 4.1 to comply with MLB rules & 8 & & 0.5 \\
\hline 4.2 to comply with NCAA rules & 8 & & 0.5 \\
\hline
\end{tabular}

Of course, there would be a paragraph explaining each of these short evaluation criteria tags. The abbreviations would be explained in these paragraphs.

\subsection{Anchoring and the Status Quo}

The order in which the alternatives are listed has a big effect on the values that humans give for the evaluation data (Piattelli-Palmarini, 1994; Tversky \& Shafir, 1992). Therefore, tradeoff study matrix should be filled out row by row and the status quo should be the alternative in the first column. This will make the evaluation data for the status quo the anchors for estimating the evaluation data for the other alternatives. This is good because the anchoring alternative is known, is consistent, and you have control over it (Smith et al., 2007).

Note: The status quo will probably have low evaluation data values (inputs for scoring functions) for performance, cost, schedule and risk. If the status quo had high performance values, then you probably would not be trying to replace it. The status quo already exists, so (1) it will not be expensive, which gives it a low (good) value for cost, (2) it should not have schedule problems, which gives it a low (good) value for schedule and (3) it should also be low risk.

Recommendation: Put the status quo alternative in the first column. In the first iteration, evaluate the scores left to right and in the next iteration evaluate them right to left. The more alternatives that exist and the more complicated the decision, the more the status quo will be favored. Do not needlessly increase the number of alternatives in a tradeoff study. More alternatives increase the difficulty of the decision. However, in the very beginning of a project it is good to have many alternatives in order to better understand the problem and the requirements. View the problem from different perspectives. Use different starting points. When estimating values for parameters of scoring functions, think about the whole range of expected values for the parameters.

Table 5. Team Excerpt for ranking process alternatives

\begin{tabular}{|l|l|l|l|l|l|l|l|l|l|l|l|l|l|l|l|}
\hline Criterion & 1 & & 2 & & 3 & & 4 & & 5 & & 6 & & 7 & $\begin{array}{l}\text { Max } \\
\text { Score }\end{array}$ \\
\hline $\begin{array}{l}\text { Metric } \\
\text { Value }\end{array}$ & 1.8 & & 0.7 & & 2.3 & & 1.5 & & 0.7 & & 1 & & 2 & & 100 \\
\hline & Raw & Wtd & Raw & Wtd & Raw & Wtd & Raw & Wtd & Raw & Wtd & Raw & Wtd & Raw & Wtd & Solution \\
\hline Alternative & Scr & Scr & Scr & Scr & Scr & Scr & Scr & Scr & Scr & Scr & Scr & Scr & Scr & Scr & Score \\
\hline Solution 1 & 2 & 7.2 & 10 & 6.3 & 9 & 14 & 3 & 9 & 3 & 2.1 & 8 & 2 & 2 & 4 & 41.8 \\
\hline Solution 2 & 9 & 3.6 & 7 & 7 & 9 & 21 & 9 & 4.5 & 2 & 1.4 & 2 & 8 & 10 & 20 & 76.6 \\
\hline Solution 3 & 3 & 16 & 2 & 4.9 & 4 & 9.2 & 8 & 14 & 3 & 2.1 & 8 & 9 & 1 & 2 & 67.3 \\
\hline Solution 4 & 9 & 5.4 & 10 & 1.4 & 5 & 12 & 9 & 12 & 9 & 6.3 & 9 & 8 & 10 & 20 & 76.6 \\
\hline Solution 5 & 3 & 16 & 3 & 7 & 5 & 12 & 8 & 14 & 8 & 5.6 & 7 & 9 & 2 & 4 & 67.3 \\
\hline Solution 6 & 9 & 16 & 3 & 2.1 & 5 & 12 & 9 & 11 & 9 & 6.3 & 5 & 7 & 10 & 20 & 76.6 \\
\hline Solution 7 & 3 & 5.4 & 8 & 5.6 & 9 & 21 & 7 & 11 & 3 & 2.1 & 5 & 5 & 9 & 18 & 67.3 \\
\hline
\end{tabular}




\begin{tabular}{|l|l|l|l|l|l|l|l|l|l|l|l|l|l|l|l|}
\hline $\begin{array}{l}\text { Do } \\
\text { Nothing }\end{array}$ & 10 & 18 & 10 & 7 & 10 & 23 & 10 & 15 & 10 & 7 & 10 & 10 & 10 & 20 & 100 \\
\hline
\end{tabular}

Why is this a mental mistake?

In a tradeoff study matrix the alternatives should be in columns, not rows, because humans find it easier to compare across rather than down. The alternatives and evaluation criteria should be identified by names, not numbers. The alternatives and evaluation criteria should be explained with sentences and paragraphs. Finally, the do nothing alternative should be in the first column.

Why is this a mental mistake?

Table 5 also shows a mistake at the implementation level: the engineers intended each weighted score to be its raw score times the metric value, and the solution score to be the summation of the weighted scores in that row. But their Excel worksheet had mistakes: only the Do Nothing row was correct.

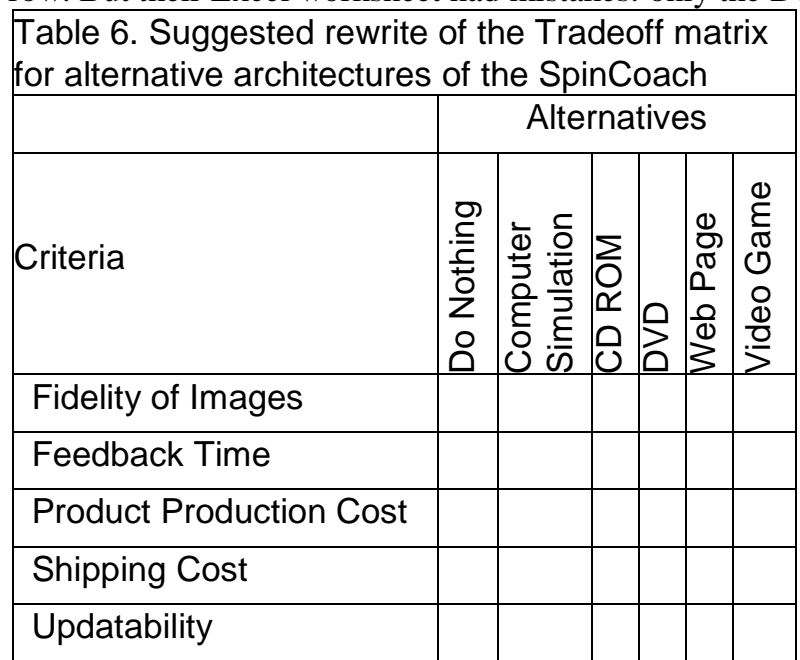

Each evaluation criterion and each alternative architecture must have a paragraph of explanation, as in the following paragraphs.

Previously, we have written that the tables and figures of a tradeoff study do not contain the evaluation criteria and the design alternatives: they merely contain tags. The actual criteria and alternatives must be explained elsewhere using sentences and paragraphs. The following is an example for the SpinCoach.

Alternative architectures for the SpinCoach

1. The Status Quo. Some batters can recognize the spin on the ball and predict its spin induced movement. But they have difficulty verbalizing this capability and teaching it to others. In batting practice, we can have the pitcher announce to the batter "curve" and then throw a curveball: announce "slider" and then throw a slider. Etc. This could be done with a human pitcher or a pitching machine.

2. Computer Simulations. Images of spinning balls can be simulated and presented on a computer monitor. This system is described in SpinTeacherGray.doc.

4. Spinning Balls. Holes are drilled into baseballs or softballs and the balls are skewered on bolts. These bolts are chucked into drills. The drills are spun at controlled speeds. Videos of this setup are on my web site. http://www.sie.arizona.edu/sysengr/baseball/index.html. Do not let someone's tie or scarf get tangled in the drills.

4. CD-ROM or DVD. Balls spinning on drills can be photographed and their images stored on CD-ROM or DVD disks. Such videos are on my web site. http://www.sie.arizona.edu/sysengr/baseball/index.html. These images along with the software program will be transferred from the CD-ROM to the user's hard disk using a license key provided by BICS. There after the user runs the SpinCoach from his or her hard disk. The user must login for each session. The information gathered at login is used to track user performance history. System upgrades will be provided with new CD-ROMs.

5. Web-based Application. Balls spinning on drills can be photographed and their images stored on the BICS web server. Such videos are on my web site. http://www.sie.arizona.edu/sysengr/baseball/index.html. These images along with the software program will be on an Internet accessible web site. This system will be based on the Apache web server with web pages written in PHP or HTML and video clips in AVI format. Access to the system will be granted by monthly subscription and login based authentication control. The user will have a profile in the system and can access this profile from any terminal connected to the Internet. The system will store user information in a database. This 
information is used to track user performance history. System upgrades can be made on the web site at any time and will be transparent to the user.

6. Make it into a video game and sell it to Nintendo, Sony or Microsoft.

Evaluation criteria for the SpinCoach

Fidelity of Images. How realistic are the images? Are they two or three-dimensional? What is the resolution? What is the color depth? What is the update rate? Will the presentation vary depending on the processor speed or the communications bandwidth? For example, would the system degrade with a dialup telephone connection to the Internet? This criterion traces to the Operational Concept Description (OCD). Importance weight is 6.

Feedback Promptness. The system shall provide positive or negative feedback to the player after each prediction. The system shall provide this feedback to the player within 500 milliseconds of the player's response. This will be a Boolean (yes or no) function. This traces to customer requirement 10. Importance weight is 10.

Product Production Cost is a measure of how much it will cost in U. S. dollars for BICS to produce one unit of the product. A monotonic decreasing scoring function shall be used $(\mathrm{L}=0, \mathrm{~B}=10, \mathrm{~S}=-0.1, \mathrm{U}=500)$. Input range is 0 to 500 dollars, baseline is 10 dollars and slope is -0.1 . This traces to customer requirement 1 . Importance weight is 6 .

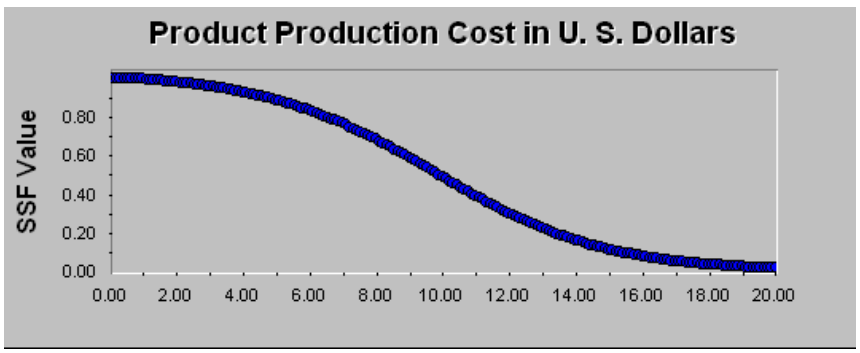

Figure 2. A scoring function for the Product Production Cost evaluation criteria

The Shipping Cost evaluation criterion is composed of Shipping Weight, Shipping Expenses, Shipping Effort and Billing Cost per unit. A scoring function is not necessary if the subcriteria have scoring functions and normalized weights. Our target value is ten dollars. This traces to customer requirement 1. Importance weight is 5 .

Updatability. This criterion evaluates how easy and convenient updates are expected to be. The system shall be continually improved and updated throughout the system life cycle. Corrective maintenance such as bug fixes should be performed within weeks. Adaptive maintenance, which includes revisions necessary to allow the system to run on new or improved hardware and software, should be accomplished in a monthly time frame. Performance and functional updates will be performed yearly. This should trace to the business plan. Importance weight is 5 .

\subsection{Treating Gains and Losses Equally}

People do not treat gains and losses equally. Kahneman earned the Nobel Prize for explaining the fact that people prefer to avoid losses rather than to acquire gains. Prospect Theory (Kahneman \& Tversky, 1979) suggests that psychologically losses are twice as powerful as gains. Would you rather get a 5\% discount, or avoid a 5\% penalty? Most people would rather avoid the penalty. In a tradeoff study, you will get a different result if the scoring function expresses losses rather than gains (Abdellaaoui, 2000) (Smith et al., 2007).

Recommendation: Human unequal treatment of gains and losses suggests that scoring functions in a tradeoff study should uniformly express either gains or losses. Principles of linguistic comprehensibility suggest that criteria should be worded in a positive manner, so that more is better. For example, use Uptime rather than Downtime, Mean Time Between Failures rather than Failure Rate, and Probability of Success rather than Probability of Failure. Finally, when using scoring functions, make sure that more output is better.

Team Excerpt

2.2 Number of Complaints

2.3 Number of Problems with the System

3.1 Number of Accidents per visit.

2.5.3. Number of Curses per day

5.2.6. Injury -- Is it possible for the design to inflict bodily injury on the batter? This rated by the players on a scale of $1-10$ ( 1 being no bodily harm, 10 being serious injury requiring hospitalization).

Why is this a mental mistake?

These criteria are phrased negatively.

Suggested rewrite 
2.2 Customer Approval Rating (\%)

2.3 Mean Time to Failure (MTTF)

3.1 Number of accident-free visits

2.5.3 Time without cursing

5.2.6. Safety - Mean time between injuries.

Second Team Excerpt

3.5.2.6 Availability of system

This figure of merit measures the availability of the system, in terms of the number of hours per year for which the system is unavailable during working hours due to failure or unscheduled maintenance.

3.5.2.7 Safety of system

This figure of merit measures the safety of the system in terms of injuries caused by the system.

Why is this a mental mistake?

Evaluation criteria should be phrased so that more is better. Availability of System and Safety of System contradict themselves. The titles are phrased positively, but the descriptions contain the negative words unavailable and injuries.

Suggested rewrite

3.5.2.6 System Availability

This criterion is the percent of time that the system is available during working hours, average per week.

3.5.2.7 System Safety

The units for this criterion are the number of days that the system has operated without an injury.

3.10 Not Using Scoring Functions

Evaluation data are transformed into normalized scores by scoring functions (utility curves) or qualitative scales (fuzzy sets). The shape of scoring functions should ideally be determined objectively, but often, subjective expert opinion is involved in their preparation. Creating scoring function packages takes time and effort (Bahill, 2008). A scoring function package should be created by a team of analysts, and be reevaluated with the stakeholders with each use. Most tradeoff studies that we have observed in industry did not use scoring functions. In some cases, scoring functions were explained in the company process, but they were not convenient, hence they were not used (Smith et al., 2007).

Recommendation: Wymorian standard scoring functions (or similar scoring functions, fuzzy sets or utility functions) should be used in tradeoff studies. Easy-to-use scoring functions should be referenced in company processes.

Team excerpt:

Many teams just did not use scoring functions.

Evaluation data are transformed into normalized scores by scoring functions (Wymore, 1993, pp. 385-398; Daniels, Werner \& Bahill, 2001). The shape of scoring functions should ideally be determined objectively, but often, subjective expert opinion is involved in their preparation. Scoring functions are also called utility functions, utility curves, value functions, normalization functions and mappings. Evaluation criteria should always have scoring functions so that the preferred alternatives do not depend on the units used. For example, see what would happen if you were to add values for something that cost about one hundred dollars and lasted about a millisecond.

Alt-1 cost a hundred dollars and lasts one millisecond, Sum $=100.001$.

Alt-2 only cost ninety-nine dollars but it lasts two millisecond, Sum $=99.002$.

The duration does not have any effect on the decision. A simple program that creates scoring functions is available free at http://www.sie.arizona.edu/sysengr/slides. It is called the Wymorian Scoring Function tool. An example of a scoring function was given in Figure 2 for the Product Production Cost.

Scoring functions must state the units for the input: for example, actual dollar values will be used as input to a cost scoring function. Without scoring functions, the preferred alternative would depend on the units used, for example, whether the costs were given in U. S. Dollars or British pounds. With scoring functions, this will not happen.

\subsection{Implying False Precision}

The most common mistake that we have seen in tradeoff studies is implying false precision. For example, a tradeoff analyst might ask a subject matter expert to estimate values for two criteria. The expert might say something like, "The first criterion is about 2 and the second is around 3." The analyst puts these numbers into a calculator and computes the ratio as 0.666666667 . This is nonsense, but nine digits might be used throughout the tradeoff study. The Forer Effect might explain this. The analyst believes that the calculator is an impeccable authority in calculating numbers. Therefore, what the calculator says must be true (Smith et al., 2007). 
Recommendation: Use significant figures methodology. Furthermore, in numerical tables, print only a sufficient number of digits after the decimal place as is necessary to show a difference between the preferred alternatives.

Team Excerpt

5.3.1.1 Trade-off scores

Concept 1: Customer chooses the bat $0.6 * 0.22500+0.4 * 0.41435=0.30074$

Concept 2: Store owner chooses the bat $0.6 * 0.25125+0.4 * 0.41435=0.31649$

Concept 3: BatChooser chooses the bat $0.6 * 0.67500+0.4 * 0.96840=0.79236$

Concept 4: BatSelect Chooses with the help of the BatChooser $0.6 * 0.84280+0.4 * 0.96840=0.89304$

Presenting five digits after the decimal point obfuscates the equations and does not help to differentiate between the alternatives.

\section{Suggested rewrite}

\subsubsection{Trade-off scores}

Concept 1: Customer chooses the bat $0.6{ }^{*} 0.23+0.4 * 0.41=0.30$

Concept 2: Storeowner chooses the bat $0.6 * 0.25+0.4 * 0.41=0.32$

Concept 3: BatChooser chooses the bat $0.6 * 0.68+0.4 * 0.97=0.79$

Concept 4: BatSelect chooses the bat with the help of the BatChooser

$$
0.6 * 0.84+0.4 * 0.97=0.89
$$

\begin{tabular}{|l|c|c|}
\hline \multicolumn{3}{|l|}{$\begin{array}{l}\text { Table 7. Second Team Excerpt for Bat } \\
\text { Chooser }\end{array}$} \\
\hline Concept & $\begin{array}{c}\text { Weighted } \\
\text { Score }\end{array}$ & Ranking \\
\hline Concept 1 Score & 0.4414 & 7 \\
\hline Concept 2 Score & 0.5420 & 4 \\
\hline Concept 3 Score & 0.2196 & 8 \\
\hline Concept 4 Score & 0.6728 & 2 \\
\hline Concept 5 Score & 0.6558 & 3 \\
\hline Concept 6 Score & 0.4652 & 6 \\
\hline Concept 7 Score & 0.6802 & 1 \\
\hline Concept 8 Score & 0.4860 & 5 \\
\hline
\end{tabular}

\begin{tabular}{|l|c|c|}
\hline \multicolumn{3}{|l|}{ Table 8. Suggested rewrite for the Bat Chooser } \\
\hline Alternative & $\begin{array}{c}\text { Weighted } \\
\text { Score }\end{array}$ & Ranking \\
\hline Concept 1 & 0.44 & 7 \\
\hline Concept 2 & 0.54 & 4 \\
\hline Concept 3 & 0.21 & 8 \\
\hline Concept 4 & 0.67 & 2 \\
\hline Concept 5 & 0.65 & 3 \\
\hline Concept 6 & 0.46 & 6 \\
\hline Concept 7 & 0.68 & 1 \\
\hline Concept 8 & 0.48 & 5 \\
\hline
\end{tabular}

\begin{tabular}{|l|c|c|}
\hline Table 9. Team Excerpt for the SpinCoach \\
\hline $\begin{array}{l}\text { Performance } \\
\text { Requirements }\end{array}$ & Value & $\begin{array}{c}\text { Normalized } \\
\text { weight }\end{array}$ \\
\hline
\end{tabular}




\begin{tabular}{|c|c|c|}
\hline 1. Accuracy & 8 & 0.235294 \\
\hline 1.1 Spin Rate & 10 & 0.384615 \\
\hline 1.2 Launch Angle & 8 & 0.307692 \\
\hline 1.3 Launch Speed & 8 & 0.307692 \\
\hline 2. Consistency & 7 & 0.205882 \\
\hline 3. Ease of Use & 6 & 0.176471 \\
\hline 3.1 Portability & 6 & 0.260870 \\
\hline 3.2 Location & 7 & 0.304348 \\
\hline 3.3 \# of Operators & 10 & 0.434783 \\
\hline 4. Opportunity & 8 & 0.235294 \\
\hline 5. Feedback & 5 & 0.147059 \\
\hline
\end{tabular}

Why is this a mental mistake?

The original Value data have one significant digit. Therefore, the normalized weights certainly should not have six digits after the decimal point.

\begin{tabular}{|c|c|c|c|}
\hline Evaluation Criteria & 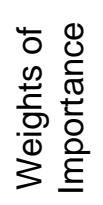 & 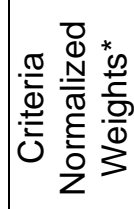 & 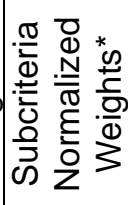 \\
\hline 1. Accuracy & 8 & 0.24 & \\
\hline 1.1 Spin Rate & 10 & & 0.38 \\
\hline 1.2 Launch Angle & 8 & & 0.31 \\
\hline 1.3 Launch Speed & 8 & & 0.31 \\
\hline 2. Consistency & 7 & 0.21 & \\
\hline 3. Ease of Use & 6 & 0.18 & \\
\hline 3.1 Portability & 6 & & 0.26 \\
\hline 3.2 Location & 7 & & 0.30 \\
\hline $\begin{array}{ccc}3.3 & \text { Number } & \text { of } \\
\text { Operators } & & \end{array}$ & 10 & & 0.43 \\
\hline 4. Opportunities per Hour & 8 & 0.24 & \\
\hline 5. Feedback Response Time & 5 & 0.15 & \\
\hline \multicolumn{4}{|c|}{$\begin{array}{l}\text { *Significant figures methodology suggests that the } \\
\text { normalized weights should only have one significant } \\
\text { digit. But here we have used two to make the } \\
\text { calculations obvious. }\end{array}$} \\
\hline
\end{tabular}

Table 10 has also put the criteria and subcriteria weights in separate columns. All of the subcriteria weights for a particular criteria sum to 1.0. All of the criteria weights sum to 1.0 .

On the other hand, Table 5 shows an example not of false precision, but of inconsistent precision. In some columns, Excel is set to display integers while in others it is set to one decimal place.

When determining how many digits should be printed consider (1) how many digits are necessary to differentiate between the preferred alternatives, (2) the sensitivity of the final recommendations to the parameters, the most sensitive parameters should be given extra resources and therefore perhaps more significant digits (Karnavas, Sanchez \& Bahill, 1993; Smith, Szidarovszky, Karnavas \& Bahill, 2008) and (3) no parameters need to be more exact than the least accurate parameter (presuming of course that the tradeoff matrix is as described in this paper and it does not have a multi-step process for estimating any parameters).

As an example, when humans state preferences between risky prospects, their judgments are not linear in probability. Humans overweight small probabilities and underweight high probabilities. This has been modeled with several different equations (Abdellaoui, 2000; Bleichrodt \& Pinto, 2000). 


$$
\begin{aligned}
& w(p)=\frac{p^{\gamma}}{\left[p^{\gamma}+(1-p)^{\gamma}\right]^{\frac{1}{\gamma}}} \\
& w(p)=\frac{\delta p^{\gamma}}{\left[\delta p^{\gamma}+(1-p)^{\gamma}\right]}
\end{aligned}
$$

and

$$
w(p)=\exp \left(-\beta(-\ln p)^{\alpha}\right) .
$$

In these equations $w$ is the probability weighting function, $p$ is the probability of a particular prospect, $\gamma, \delta, \alpha$ and $\beta$ are parameters fit to experimental data of individual humans. Now the question becomes, Should a tradeoff analyst use equations like these when eliciting information for a tradeoff study? The answer depends on the accuracy of the other parameters. In all of the design documents that we examined, the weights of importance had only one significant digit. Therefore correcting for each human's incorrect estimation and use of probabilities is not warranted. In a tradeoff study, the number of significant figures should be determined for each parameter. Then resources should not be committed to increasing the number of significant figures for any except the most important and the least precise parameters.

\subsection{Obviating Expert Opinion}

An analyst could hold a circular belief that expert opinion or review is not necessary, because no evidence for the need of expert opinion is present. This is especially true if no expert has ever been asked to comment on the tradeoff study (Smith et al., 2007).

Recommendation: Experts should be sought, formally or informally, to evaluate the results of tradeoff studies.

The most common mistake that we have found in design projects over the last 35 years is failing to talk with stakeholders and failing to consult experts and experienced advisors. The university and local industry is full of experts in the fields of every project that we have done. In this time, very few teams have sought advice from domain experts. Why do people fail to seek out the advice of experts and experienced advisors? The students rated the following possible reasons. In each category, the reasons are arranged from the most frequent to the least.

It was common for our teams to not seek outside advice or guidance in the course of performing their tradeoff studies. If they had sought this guidance, expert review or opinion, they might have avoided the errors we detected in their tradeoff studies. This would most likely be the case if the guidance concerned the tradeoff study itself (not just the technical matters) and elicited high-quality examination of all tradeoff study components.

Table 11. Possible reasons for failing to talk with stakeholders, experts and advisors.

Timidity

Perhaps they do not want to inconvenience the wise men or waste their time. However, people are not reluctant to seek the advice of physicians, tax accountants and lawyers. To overcome timidity, before you talk to an expert, you should formulate your questions and explain your problem in a way that the expert can quickly understand. Tailoring a message and formulating the right questions is hard and must be done iteratively. Before you leave your meeting, you should state what you think the expert said, to make sure that you understood and to prevent having to go back later for clarification.

Perhaps they are shy or intimidated by experts.

Perhaps they fear that the incompleteness of their project will be interpreted as incompetence.

Perhaps they think that a face-to-face meeting would display their naïveté. This is not a problem with e-mails, because most people do not expect e-mails to be thoughtful, coherent and grammatically correct: most students do not edit their e-mails or use a spelling and grammar checker on them.

Perhaps they think that seeking advice reveals their ignorance, and that ignorance is shameful.

Perhaps they think that consulting experts shows weakness, whereas going it alone shows strength.

Perhaps they feel that, because they do not have a charge number, they cannot ask experts in their company for advice.

Perceived Value 
Perhaps they do not realize the usefulness of face-to-face meetings with experts.

Perhaps it is a matter of return on investment. Consulting experts takes time and effort. Perhaps these teams thought the improvement in their tradeoff studies would not be worth the effort of consulting experts.

Perhaps the smart people thought, "We can get an A without wasting our time talking to our advisor."

Perhaps the new technology generation thinks that they can just Google the web and get all the information that experts might provide.

Perhaps they noticed that other courses at the university do not provide world-class experts to meet with them, so it must not be important.

Perhaps they do not see a direct correlation between their grade and meetings with their advisor.

Perhaps they do not perceive added value.

Time (obviously time and perceived value will be traded off)

Perhaps they thought that they were too busy; meeting with their advisor would take time and effort; it would be hard to schedule meetings with their advisor. Maybe they were just lazy.

\section{Communication}

Perhaps they have had no experience initiating a meaningful conversation with a stranger and are therefore reluctant to do so.

Most of our students communicate with cell phones, twitter, the internet or e-mail. So they are multitaskers, jumping from task to task. Therefore, they are good at multitasking, but their attention spans are perhaps short. So they do not know how to talk face-to-face with an expert.

Other

Perhaps they have been taught that engineers work alone: after all, cooperating on exams is frowned upon. However, in the modern industrial environment, engineering is done by teams and when success is important consultants are also hired.

Perhaps they are reluctant to change or they don't want to do it someone else's way. If you ask for advice, then you should use the advice you are given.

Foreign students said, "It's embarrassing to show weakness in the English language" and "Our culture teaches us to not approach an advisor or mentor."

Similarly, the medical profession does not practice extensive consultation with experts. In one study of over 300 breast cancer surgeons (Katz et al., 2010), only one-fourth typically consulted medical oncologists, radiation oncologists or plastic surgeons prior to surgery. About two-thirds of the surgeons reported that almost none of their patients participated in patient decision-support activities, such as attending a practice-based presentation, viewing web-based materials or participating in peer-support programs.

"He who trusts in himself is a fool, but he who walks in wisdom is kept safe" (Proverbs 28; 26)

\section{Statistical Summary of Mental Mistakes}

We examined 110 project reports composed of over 8000 pages of text that had been submitted over the last two decades and we compiled the following statistics.

Type of Mental Mistake

Using Dependent Criteria

Not Stating the Problem in Terms of Stakeholder Needs

Vague Problem Statement

Substituting a Related Attribute

Sensitivity Analysis Mistakes

Forer Effect
Number of mistakes found 


$\begin{array}{lc}\text { Weight of Importance Mistakes } & 11 \\ \text { Anchoring and the Status Quo } & 69 \\ \text { Treating Gains and Losses Equally } & 46 \\ \text { Not Using Scoring Functions } & 32 \\ \text { Implying False Precision } & 59 \\ \text { Obviating Expert Opinion } & 85 \\ \text { Other Mental Mistakes } & 128\end{array}$

In these 110 tradeoff study reports, we found 808 mental mistakes. We put these in a spreadsheet. Then for 100 of these mental mistakes, we made example cases using (1) direct quotes from the original reports, (2) an explanation of the mistake, (3) related paragraphs from Smith et al. (2007) and (4) recommended revisions. We used a format similar to that used in this paper. Based on the perceived heuristic value, uniform coverage of the 12 mental mistakes and minimization of the number of projects that would have to be explained, we selected the two dozen development cases (team excerpts) that are in this paper, and another 50 cases that were used for testing. Then 20 Raytheon engineers and 50 University of Arizona students tried to identify the mental mistakes in the 50 excerpts of the test set. The average agreement was about $80 \%$.

In general, we found no correlation between the number of mistakes we detected and the students' grades on the reports. There are several reasons for this. First, the reports with the highest grades were usually written better and they were therefore easier to understand. The better we understand something the easier it is to find and identify mental mistakes in it. Second, the better reports tended to be longer and more complete, and thus there was more opportunity for mental mistakes. On the other hand, the poor reports showed more instances of mistakes of omission, such as failure to use scoring functions, incomplete sensitivity analyses and failure to get advice from experts.

\section{Who Cares?}

Who cares about mistakes in doing tradeoff studies? Perhaps everyone should. If a tradeoff study is not performed or is done badly it could cost a company a lot of money. As an example will now consider the San Diego Airport Site Selection Tradeoff Study. This is a large, expensive, publicly accessible tradeoff study that contains mental mistakes like those we present in this paper. This tradeoff study took six years and cost 17 million dollars. When its results were presented to the voters in November of 2006 , the voters turned the proposal down and the $\$ 17 \mathrm{M}$ was wasted. Some mistakes might have been made in conducting this tradeoff study.

They did a tradeoff study, but only four of the ten tradeoff study components were utilized: Problem Statement, Alternate Solutions, Evaluation Criteria and Preferred Alternatives.

They used five evaluation criteria: Aeronautical, Environmental, Market, Military and Financial. The criteria were arranged hierarchally with subcriteria and subsubcriteria. However, the criteria did not have weights of importance or scoring functions.

They had a dozen alternative sites, including the Do Nothing alternative. They often added and deleted alternatives. For example, the floating platform in the Pacific Ocean was dismissed early. The Campo and Borrego Springs sites were added late, so these sites had greater visibility in the public mind. However, the Campo and Borrego Springs sites were similar so, because of distinctiveness by addition of alternatives, they faded away.

They did a rudimentary sensitivity analysis looking at changes in their planning parameters at two different demand levels. They also did a small sensitivity analysis showing changes in total cost as a function of available funding (without issuing bonds or increasing taxes).

The interim results of the study were continually being reported in the press. So they certainly received a lot of expert opinions. However, in the end, the voters did not trust the study. The objectivity of the Regional Airport Authority that conducted the study was questioned. It appeared over time that the Authority was more interested in supporting a particular airport site than in explaining the various options for the voters. The Authority was perceived as being pro-business and anti-military. The difficulties of military and civilian joint use were not ameliorated. San Diegans were happy with the status quo: Lindberg Field was good for its community and the Marine Corps Air Station was good for its community. The Authority did not show a burning platform or a compelling reason for change. It seemed that they only considered future business growth.

The ballot proposal asked, "Should Airport Authority and government officials work toward obtaining 3,000 acres at MCAS Miramar by 2020 for a commercial airport, providing certain conditions are met?" It was turned down $38 \%$ to 
$62 \%$. We are not saying that if they had done a more thorough tradeoff study, then the ballot proposal would have passed. We are only saying that they could have done a better tradeoff study.

\section{Summary}

Good industry practices for improving the probability of success of tradeoff studies include having teams evaluate the data, evaluating the data in many iterations and expert review of the results and recommendations. It is important that the review teams have a substantial number of reviewers that are external to the project and that the reviewers consider design decisions as well as simple checking to ensure that tasks were done. Reviews are often hampered by failure to allow external reviewers access to proprietary or classified data. To improve your tradeoff study process you should inform your decision makers about how mental mistakes affect tradeoff studies (forewarned is forearmed), encourage a long-term institutional decision horizon, use a team approach with frequent iterations and institute both expert and public reviews. Finally try to reduce mental mistakes by using the recommendations of this paper.

The literature on Decision Making, Cognitive Science and Experimental Economics contains hundreds of experiments showing persistent human mistakes of judgment. Smith et al. (2007) postulated 28 specific types of mental mistakes that could affect the ten specific components of a tradeoff study. This paper has shown examples in a dozen categories of mental mistakes that systems engineers have actually made while creating tradeoff studies. The research found over eight hundred examples of such mistakes: these examples prove that systems engineers really do make such mistakes.

\section{References}

Abdellaaoui, M. (2000). Parameter-free elicitation of utility and probability weighting functions, Management Science, 46(11), 1497-1512. http://dx.doi.org/10.1287/mnsc.46.11.1497.12080

Bahill, A. T. (2008). Decision Making and Tradeoff Studies, http://www.sie.arizona.edu/sysengr/slides/decisionMaking.ppt, last accessed March 2010.

Bahill, A. T., \& Baldwin, D. G., (2007). Describing baseball pitch movement with right-hand rules, Computers in Biology and Medicine, 37, 1001-1008. http://dx.doi.org/10.1016/j.compbiomed.2006.06.007

Bahill, A. T., \& Baldwin, D. G. (2008). Mechanics of baseball pitching and batting, Chapter 16 Applied Biomedical Engineering Mechanics, Dhanjoo Ghista, CRC Press and Taylor \& Francis Asia Pacific, pp. 445-488.

Bahill, A. T., Baldwin, D. G., \& Ramberg, J. S. (2009). Effects of altitude and atmospheric conditions on the flight of a baseball, International Journal of Sports Science and Engineering, 3(2), 109-128. ISSN 1750-9823 (print). http://www.worldacademicunion.com/journal/SSCI/online.htm

Bahill, A. T., Baldwin, D. G., \& Venkateswaran, J. (2005). Predicting a baseball's path, American Scientist, 93(3), 218-225.

Bahill, A. T., \& Dean, F. F. (1999, 2009). Discovering system requirements, Chapter 4 in Handbook of Systems Engineering and Management, A.P. Sage \& W.B. Rouse (Eds), John Wiley \& Sons, first edition 175-220, 1999, second edition, 205-266.

Bahill, A. T., \& Karnavas, W. J. (2000). Risk analysis of a pinewood derby: A case study, Systems Engineering, 3(3), 143-155. http://dx.doi.org/10.1002/1520-6858(200033)3:3<143::AID-SYS3>3.0.CO;2-0

Bahill, A. T., \& LaRitz, T. (1984). Why can't batters keep their eyes on the ball, American Scientist, 72, 249-253.

Bahill, A. T., \& Smith, E. (2009). An industry standard risk analysis technique, Engineering Management Journal, 21(4), 16-29.

Bahill, A. T., \& Stark, L. (1975). Neurological control of horizontal and vertical components of oblique saccadic eye movements, Mathematical Biosciences, 27, 287-298. http://dx.doi.org/10.1016/0025-5564(75)90107-8

Bahill, A. T., \& Stark, L. (1977). Oblique saccadic eye movements: Independence of horizontal and vertical channels, Archives of Ophthalmology, 95, 1258-1261. http://dx.doi.org/10.1001/archopht.1977.04450070156016

Baldwin, D. G., Bahill, A. T., \& Nathan, A. (2007). Nickel and dime pitches, Baseball Research Journal, 35, 25-29.

Bleichrodt, H., \& Pinto, J. L. (2000). A parameter-free elicitation of the probability weighting function in medical decision analysis, Management Science, 46(11), 1485-1496. http://dx.doi.org/10.1287/mnsc.46.11.1485.12086

Chapman, W. L., Bahill, A. T., \& Wymore, A. W. (1992). Engineering modeling and design, CRC Press Inc., Boca Raton, FL.

Chrissis, M. B., Konrad, M., \& Shrum, S. (2003). CMMI: Guidelines for Process Integration and Product Improvement, Pearson Education Inc., Boston. 
CMMI for Development, ver. 1.3, (2010). Software Engineering Institute, Pittsburgh, PA, http://cmmiinstitute.com/resource/cmmi-for-development-version-1-3-microsoft-word/ Retrieved November 2013

Daniels, J. P., \& Bahill, A. T. (2004). Hybrid process combines traditional requirements and use cases, Systems Engineering, 7(4), 303-319. http://dx.doi.org/10.1002/sys.20013

Daniels, J., Werner, P., \& Bahill, A. T. (2001). Quantitative methods for tradeoff analyses, Systems Engineering, 4(3) 190-212. http://dx.doi.org/10.1002/sys.1016

Forer, B. R. (1949). The fallacy of personal validation: A classroom demonstration of gullibility, Journal of Abnormal Psychology, 44, 118-121. http://dx.doi.org/10.1037/h0059240

Hanselmann, M., \& Tanner, C. (2008). Taboos and conflicts in decision making: sacred values, decision difficulty, and emotions, Judgment and Decision Making, 3(1), 51-63.

Hooks, F., \& Farry, K. A. (2001). Customer-centered products: Creating successful products through smart requirements management, AMACOM, New York.

Hsu, F. K., Bahill, A. T., \& Stark, L. (1976). Parametric sensitivity of a homeomorphic model for saccadic and vergence eye movements, Computer Programs in Biomedicine, 6, 108-116. http://dx.doi.org/10.1016/0010-468X(76)90032-5

Hull, E., Jackson, K., \& Dick, J. (2005). Requirements engineering, Springer, London.

INCOSE Systems Engineering Handbook v3.2.2, (2011). Retrieved November 2013 http://www.incose.org/ProductsPubs/incosestore.aspx

Kahneman, D. (2002). Maps of bounded rationality: a perspective on intuitive judgment and choice, Nobel Prize Lecture, December 8, 2002, this site also has a video of the speech, http://nobelprize.org/nobel_prizes/economics/laureates/2002/kahneman-lecture.html

Kahneman, D. (2003). A perspective on judgment and choice: Mapping bounded rationality, American Psychologist, 58(9), 697-720. http://dx.doi.org/10.1037/0003-066X.58.9.697

Kahneman, D., \& Tversky, A. (1979).Prospect theory: An analysis of decision under risk, Econometrica, 46(2), 171-185.

Karnavas, W. J., Sanchez, P. J., \& Bahill, A. T., (1993). Sensitivity analyses of continuous and discrete systems in the time and frequency domains, IEEE Transactions on Systems, Man and Cybernetics, SMC-23, 488-501. http://dx.doi.org/10.1109/21.229461

Katz, S. J., Hawley, S. T., Morrow, M., Griggs, J. J., Jagsi, R.., Hamilton, A. S., Graff, J. J., Friese, C. R., \& Hofer, T. P. (2010). Coordinating cancer care: patient and practice management processes among surgeons who treat breast cancer, Medical Care, 48(1), 45-51. http://dx.doi.org/10.1097/MLR.0b013e3181bd49ca

Keeney, R. L. (1992). Value-focused thinking: A path to creative decision making, Harvard University Press, Cambridge, MA.

Marquard, L., \& Robinson, S. M. (2008). Reducing perceptual and cognitive challenges in making decisions with models, in Decision Modeling and Behavior in Complex and Uncertain Environments, Eds. T. Kugler, J. C. Smith, T. Connolly \& Y. J. Son., Springer, Science+Business Media, NY, NY, pp. 33-55.

McBeath, M. K., Nathan, A. M., Bahill, A. T., \& Baldwin, D. G. (2008). Paradoxical pop-ups: Why are they hard to catch? American Journal of Physics, 76(8), 723-729. http://dx.doi.org/10.1119/1.2937899

Piattelli-Palmarini, M. (1994). Inevitable illusions: How mistakes of reason rule our minds, John Wiley \& Sons, New York.

RSAS, Press release: Nobel Prize in Economics 2002, Retrieved September 2008 from The Royal Swedish Academy of Sciences: http://nobelprize.org/nobel_prizes/economics/laureates/2002/press.html.

San Diego Airport Site Selection, http://www.san.org/documents/sdcraa/archives/Airport\%20Site\%20Selection\%20Program/Technical\%20Analysis/ Financial\%20Comparative\%20Analysis\%20Presentation.pdf Accessed November 2013.

Sage, A. P. (1981). Behavioral and organizational considerations in the design of information systems and processes for planning and decision support, IEEE Transactions on Systems, Man and Cybernetics, SMC-11(9) 640-680. http://dx.doi.org/10.1109/TSMC.1981.4308761 
Smith, E. D., Piattelli-Palmarini, M., \& Bahill, A. T., (2008). Cognitive biases affect the acceptance of tradeoff studies, in Decision Modeling and Behavior in Complex and Uncertain Environments, Eds. T. Kugler, J. C. Smith, T. Connolly \& Y. J. Son., Springer, Science+Business Media, NY, NY, pp. 227-249.

Smith, E. D., Son, Y. J., Piattelli-Palmarini, M., \& Bahill, A. T., (2007). Ameliorating the effects of cognitive biases on tradeoff studies, Systems Engineering, 10(3), 222-240. http://dx.doi.org/10.1002/sys.20072

Smith, E. D., Szidarovszky, F., Karnavas , W. J., \& Bahill, A. T. (2008). Sensitivity analysis, a powerful system validation technique, The Open Cybernetics and Systemics Journal, 2, 39-56. http://dx.doi.org/10.2174/1874110X00802010039.

Tversky, A., \& Shafir, E. (1992). The disjunction effect in choice under uncertainty, Psychological Science, 3(5), 305-309. http://dx.doi.org/10.1111/j.1467-9280.1992.tb00678.x

Wymore, A. W. (1993). Model-based systems engineering, CRC Press Inc., Boca Raton, FL.

Zhu, A., Aurum, I., Gorton. \& Jeffery, R. (2005). Tradeoff and sensitivity analysis in software architecture evaluation using analytic hierarchy process, Software Quality Journal, 13(4), 357-375.

http://dx.doi.org/10.1007/s11219-005-4251-0

\section{Biographical Sketches}

James Bohlman works for Intex, a small startup making HF IR emitters for gas detection technology. He is working to specify and obtain equipment for testing and burn-in. He joined STRC a small startup in May 2008 as the senior engineer and has been involved almost from the beginning in the construction of the lab space. STRC is a research group dedicated to the purification of metallurgical-grade silicon into solar-cell useable silicon by metallurgical refination and hydrometallurgy. He attended University of Wisconsin at Madison where receiving a BS in Metallurgical and Mining Engineering. He worked at Texas Instruments in Dallas Texas in the pilot line wafer fab metallization area running sputter deposition PVD equipment. He then worked in a production wafer fab called DMOS IV processing 6" silicon wafers into one megabit DRAM memory circuits later working on application specific integrated circuits (ASICs) as the memory business went to Japan. James also worked at Analog Devices in Norwood, Massachusetts as a process engineer in metallization and implant primarily on high-end bipolar circuits customizable with a trimable $\mathrm{SiCr}$ (Silicon Chrome) resistor. Then at Burr Brown Corp., (which subsequently became Texas Instruments in 2000) he was a CVD and PECVD process engineer producing high-performance bipolar A-to-D circuits. He also worked on implementation of a special resistor process to make the parts more reliable, reducing quality issues and customer concerns. He has an MBA from the University of Phoenix and a Masters of Engineering in Systems Engineering from the University of Arizona; two degrees which complement each other in their approach to projects, systems and business.

Terry Bahill is an Emeritus Professor of Systems Engineering and of Biomedical Engineering at the University of Arizona in Tucson. He received his Ph.D. in electrical engineering and computer science from the University of California, Berkeley, in 1975. Bahill has worked with dozens of high-tech companies presenting seminars on Systems Engineering, working on system development teams and helping them to describe their Systems Engineering processes. He holds a U.S. patent for the Bat Chooser, a system that computes the Ideal Bat Weight for individual baseball and softball batters. He was elected to the Omega Alpha Association: the Systems Engineering Honor Society. He received the Sandia National Laboratories Gold President's Quality Award. He is a Fellow of the Institute of Electrical and Electronics Engineers (IEEE), of Raytheon Missile Systems, of the International Council on Systems Engineering (INCOSE) and of the American Association for the Advancement of Science (AAAS). He is the Founding Chair Emeritus of the INCOSE Fellows Selection Committee. His picture is in the Baseball Hall of Fame's exhibition "Baseball as America." You can view this picture at http://www.sie.arizona.edu/sysengr/.

\section{$(\mathrm{cc})$ EY}

This work is licensed under a Creative Commons Attribution 3.0 License. 